\title{
How to publish your manuscript successfully (with Wiley)
}

Matteo Cavalleri ${ }^{1}$

${ }^{1}$ Affiliation not available

March 19, 2021

\begin{abstract}
Part of the training module on publishing with the Council of Australian University Librarians, this 1h webinar provides tips to Early Career Researchers on how to write and accompany an article through the peer-review process. Not specific to Wiley journals, but why go elsewhere, really?
\end{abstract}

Rich media available at https://speakerdeck.com/teowaits/how-to-publish-your-manuscriptsuccessfully-with-wiley

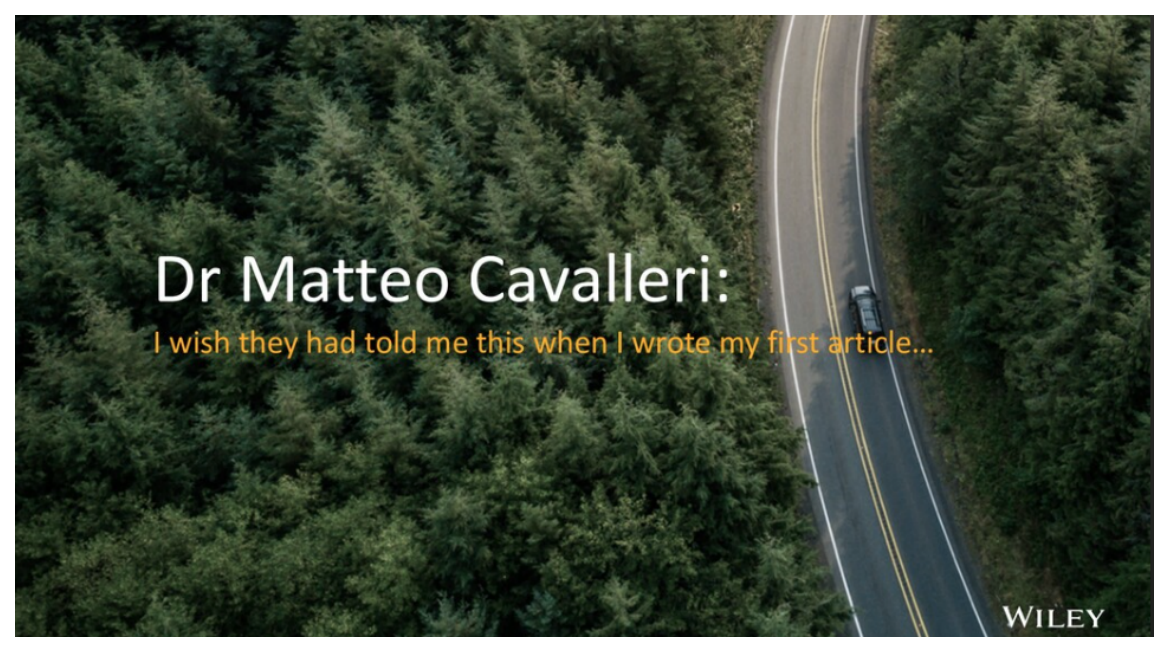

Figure 1: "Things I wished I knew when I wrote my first article" is a good alternative title for this talk. 